\title{
Meta Cognitive Strategy Use: Off or On in Online Reading
}

\author{
Inaam Darwish
}

\begin{abstract}
Much research has examined the role of metacognition in reading printed texts in both L1 and L2 (Pressley, 2000). Today's learners have to use internet technologies to succeed academically. However, reading online is different than reading texts in print; more specifically since new reading strategies and skills are needed for efficiently reading on the web (Coiro \& Dobler, 2007; Kymes, 2007). Despite the prevalence of online reading in academic contexts, little research has investigated the use of metacognitive strategies in online reading (Huang, Chern, \& Lin, 2009; Zhang \& Duke, 2008), especially in L2 online reading. Thus, this study investigated the metacognitive strategies reported by EFL learners when reading in L2. It explored the strategies used by a sample of Lebanese EFL university students when reading English texts online. It employed the OSORS questionnaire (Anderson, 2003). The questionnaires were administered to 250 university students and descriptive analysis was conducted through SPSS. The results of the survey revealed that learners reported low to moderate strategy use when reading online. The pedagogical implications of the study and recommendations for future research are also discussed.
\end{abstract}

Keywords - Metacognition: A thinking process about thinking, or reflective processes such as planning, selecting, monitoring, orchestrating, and evaluating strategy use. Online reading: The act of reading a variety of sources on the Internet, independently or with a partner.

\section{INTRODUCTION}

$\mathrm{M}$ ETACOGNITION can be defined as an individual's knowledge of his/ her own cognitive processes. It refers to the active monitoring and consequent regulation and orchestration of these processes (Flavell, 1976). In other words, it involves the knowledge of which cognitive skills are/ are to be employed in cognitive tasks as well as the ability to be able to use this knowledge to meet the goals of the task. More specifically, metacognition involves knowledge about cognition and regulation of cognition (Palnincsar \& Brown, 1987). Knowledge of cognition is the ability to reflect on one's own cognitive processes and includes knowledge about how, when, and why to employ a cognitive activity (Baker, 2005). It is divided into three sub-processes; declarative knowledge (knowing what), procedural knowledge (knowing how) and conditional knowledge (knowing why or when).

\section{Lebanese University, Lebanon}

On the other hand, regulation of cognition relates to the use of strategies that allow individuals to control their cognitive activities and includes three key elements: planning, monitoring and evaluation. In the context of reading, this can refer to the planning, monitoring, revising and evaluation of the reading strategies used by readers during reading (Baker, 2005).

Recent research has investigated the importance of metacognitive strategies during the reading process (Andersen, 2002; Block \& Pressley, 2002, Sheorey \& Mokhtari, 2001).

In effect, O'Malley and Chamot (1990) emphasize the importance of metacognition by stating that "students without metacognitive approaches are essentially learners without direction or opportunity to plan their learning, monitor their progress, or review their accomplishments and future learning directions" (p.5). Moreover, Carrell et al (1989) consider metacognitive awareness to be a critical element of proficient, strategic reading. Anderson (2008) also states that strong metacognitive skills empower language learners since when learners reflect upon their learning, they become better prepared to make conscious decisions about what they can do to improve their learning.

A particularly influential series of studies on metacognitive reading strategies are Mokhtari and Reichard (2002), Mokhtari and Sheorey (2002), and Sheorey and Mokhtari's (2001) studies of metacognitive reading strategies used in $\mathrm{Ll}$ and $\mathrm{L} 2$ reading. They suggested three subcategories of metacognitive reading strategies: Global Reading Strategies (GLOB), Problem Solving Strategies (PROB), and Support Strategies (SUP): GLOB are those intentional, carefully planned techniques by which learners monitor or manage their reading, PROB are the actions and procedures that readers use while working directly with the text and SUP are basic support mechanism intended to aid the reader in comprehending the test. Consequently, Mokhtari and Reichard (2002) developed an instrument Metacognitive Awareness of Reading Strategies Inventory (MARSI) to measure L1 learners' metacognitive awareness of reading strategies. Mokhtari and Sheorey (2002) developed the Survey of Reading Strategies (SORS) to measure the type and frequency of ESL students' metacognitive reading strategies while reading print-based academic materials.

There has been a widespread increase in the use of technology to the extent that a fairly new form of literacy has emerged. According to the American National Broadband Plan (2010), digital literacy is a variety of cognitive and technical skills to use technology to find, evaluate, create, and communicate information. Nevertheless, many researchers state that the characteristics of print texts are different from those of online texts. Print texts are linear, bounded, static, unchanging, hierarchical, and sequential and contain a fixed format and a limited amount of information (Henry, 2005). 
However, online texts are unbounded, multilinear, open-ended, discontinuous, and unconstrained in the amount of information (Henry, 2005).

Sutherland-Smith (2002) found that readers use different strategies when reading print text than when reading digital text. The study found that reading web-based text permits nonlinear strategies of thinking, and allows nonhierarchical strategies. Similarly, Henry (2005) claims that the act of reading on the internet is fundamentally different from reading a traditional printed text and that searching on the Internet requires different literacy skills and higher-order thinking skills. And she emphasizes the role of higher order thinking skills because those are essential for successful use of the Internet. Thus, reading strategy is one important variable influencing the online reading process.

Kramarski and Feldman (2000) investigated the different metacognitive strategies used by readers in two different classroom types. The participants in the study were fifty two EFL students who studied in two eighth-grade sections participated in this study. They were divided into two groups: the internet group, exposed to metacognitive instruction embedded in an internet classroom, and the control group, exposed to metacognitive instruction embedded in a regular class. One significant finding of this study was that the control group demonstrated a significantly higher level in their metacognitive skills than the internet group did. The study concludes with a necessary recommendation for further research into metacognitive reading strategies in online environments as well as metacognitive instructional methods for using internet.

A different result was found by Anderson (2003) who investigated the online reading strategies of L2 readers. The study involved one hundred thirty-one EFL and 116 ESL students who completed the Online SORS (OSORS) to measure the metacognitive reading strategies used by EFL and ESL readers in the context of online environment. The results showed that the L2 readers in general used a lot of problem solving strategies and the EFL readers use problem solving strategies more frequently than did the ESL readers.

Similarly, Konishi (2003) reported on the kinds of strategies ESL learners use when they read through academic texts on the Internet. The participants were a group of six international students from Japan studying in the undergraduate or postgraduate levels at a university in Australia. The study shows that all participants utilized metacognitive strategies effectively when they read hypertext on the Internet. The participants in the study set their own goal of reading, monitored their understanding of the text and revised their strategy use. Most of the learners in this study reported using the same strategies in both online and printed text reading.

The above findings concerning the metacognitive strategies employed by learners during online reading reveal mixed results; thus, the purpose of this research is to further explore the strategies used by learners when reading online.

\section{II- PURPOSE OF STUDY}

The primary aim of the survey is to explore the use of metacognitive reading strategies used by university students within the context of academic online reading. The study elicits data on students' reported reading habits online and provides data on the strategies employed while reading materials for foreign language learning.

More specifically, it reports on the following questions:

1. What are the reported types of metacognitive online reading strategies used by EFL university students in Lebanon?

2. What is the distribution of the reported strategies among the three categories of global strategies, problem-solving strategies, and support strategies?

\section{III- METHODOLOGY}

\section{A. Participants}

The participants in this study were $250 \mathrm{EFL}$ students enrolled at a private university in Lebanon. The students were enrolled in the different sections of the same Advanced English Writing course. Of the 125 participating students, 65 were males and 60 were females. Students at this university are frequently asked to read resources online and complete required assignments. Most of the assignments are submitted online through each student's own account. Thus, the participants in this study are familiar with the internet and frequently read academic texts online..

\section{B. Instruments}

The OSORS is based on the Survey of Reading Strategies designed by Mokhtari and Shoerey (2001) and contains the same categories but includes more questions to cover online reading. The OSORS has 18 items for global strategies, 11 items for problem-solving strategies, and 9 items for support strategies. Anderson (2003) reported that the Cronbach's alpha for the overall OSORS was .92. The reliability for each of the three subsections was .77 for global reading strategies, .64 for problem-solving strategies, and .69 for support strategies. The reported reliabilities establish that OSORS is a reliable instrument for assessing the metacognitive online reading strategies of foreign language learners (Anderson, 2003). The OSORS has been used in various studies of metacognitive online reading strategies, including Incecay (2013), Kim (2011), Ostovar-Namaghi and Noghabi (2014).

\section{C.Data Collection and Analysis}

The participants completed the OSORS at the end of a regular class that was held at the language lab. The students had been working on an in-class research activity using the computers at the language lab. At the end of the class, the students were asked to complete the questionnaire. The data was analyzed using SPSS to quantitatively describe the extent of metacognitive strategy use and the categories of strategies that are used more frequently.

\section{IV- RESULTS AND DISCUSSION}

The participants in the study were asked to answer the questions by using five-point Likert scale. The interpretation 
of the averages for each item considered a mean of 3.5 or higher as indicative of high use of strategy, a mean of 2.5 to 3.4 as indicative of moderate use of strategy, and 2.4 or lower as indicative of low use of strategy. The distribution of the means of each subscale (Global, Problem Solving, and Support) is shown on Tables 1, 2, and 3 respectively.

The data analysis showed that the participants have reported medium metacognitive strategy use when reading online; the mean of the overall scores on the OSORS was 2.66.

The results revealed that the means of all the three subscales fall into the medium strategy use range (2.5 to 3.4$)$. The mean scores on each subscale were as follows: the mean of the Global Strategies was 2.54, the mean of the Problem Solving was 2.9, and the mean of Support Strategies was 2.545. This shows that the EFL in this study used Problem Solving strategies more than the other two categories when reading online.

The results showed that the surveyed students assessed their use of Global strategies as medium (2.54), with item means ranging from 1.15 to 4.25 . The item "Reviewing text's length and organization first" and the item "Scanning text before for the purpose" received the lowest score which reveals that students tended to ignore typographical features of the text as well as skimming and scanning as possible tools for identifying important information when reading online.

This finding is particularly interesting since all high school students in Lebanon will have received some training (to different extents) in Global strategies in their English reading classes before entering university. This is due to the fact that the national textbook employed in public schools as well as most books employed at private schools include the basic concepts of scanning, activating prior discourse and content knowledge. Thus, teachers and instructors should not assume that students are familiar with these strategies when reading online and should provide further instruction and training in how to use these global strategies when reading online.

TABLE 1

MEANS OF GLOBAL STRATEGY USE SUBSCALE

1. Have a purpose in mind when reading 2.45

2. Live chat with other learners of English 3.45

3. Live chat with native speakers of English $\quad 3.34$

5. Using background knowledge to understand text 2.67

6. Scrolling through text before reading 1.54

8. Analyzing the content for purpose of reading 2.25

10. Reviewing text's length and organization first $\quad 1.15$

14. Deciding what to focus on and what to ignore $\quad 1.90$

17. Reading online for academic purposes 3.40

18. Using tables and pictures for more understanding $\quad 2.57$

20. Using context clues to better understand the text 3.45

23. Using bold face and italics for key information. $\quad 2.57$

24. Evaluating the information in the online text. $\quad 2.10$

26. Checking understanding with new information. 2.25

27. Guessing the content while reading 2.45

30. Checking if guesses were right or wrong 2.48

32. Scanning text before for the purpose 1.50

33. Reading online for fun $\quad 4.25$

Problem Solving strategies are the strategies more frequently employed the surveyed participants. Although the mean exhibited medium use of strategies in this category, the result itself is significant since it reflects students' ability to indicate a problem they encounter when reading and might be able to take necessary action with appropriate metacognitive strategy use training. The items "Paying more attention to difficult text" and "Stopping to think about the content" received the highest score (4.2 and 3.76 respectively) however; the strategies "Visualizing information to remember" received a relatively low score. This indicates that students might be able to recognize when they face a problem; yet they might not be aware of several problem solving strategies that they can use to fix the problem. This highlights the need to familiarize students with such strategies so that they can add to their already existent strategy knowledge and use such as guessing meaning of unknown words form context (3.76) which they might have been trained on in their reading classrooms.

TABLE II

MEANS OF PROBLEM-SOLVING STRATEGIES SUBSCALE

9. Reading slowly and carefully to understand $\quad 1.80$

11. Trying to refocus when losing concentration 3.15

13. Adjusting reading speed $\quad 2.25$

16. Paying more attention to difficult text $\quad 4.20$

19. Stopping to think about the content 3.85

22. Visualizing information to remember better $\quad 1.78$

28. Re-reading for more understanding $\quad 3.15$

31. Guessing meaning of unknown words 3.76

34. Critically evaluating the text before using it $\quad 2.80$

35. Distinguishing between fact and opinion 3.29

36. Looking for sites and cover both sides of issues $\quad 2.58$

The Support strategies include the use of basic support mechanisms such as dictionaries, online reference links, highlighting and taking notes, printing a hard copy, paraphrasing information, and self-questioning.

Results showed that using a dictionary is an important strategy for the students in this study (3.87). However, note taking is not favored by many of the participants (1.8). This result highlights a need for training university students in note taking when reading online. Similarly, students revealed a low frequency in rereading a difficult text aloud which shows that there might be a need in providing university students with more active reading instruction in the form of think aloud modeling. This might help in making the students more actively engaged and more motivated to try out new or otherwise non-opted for support strategies like reading aloud and paraphrasing.

TABLE III

MEANS FOR SUPPORT STRATEGIES SUBSCALE

4. Taking notes to help in understanding 1.85

7. Reading aloud when text is difficult $\quad 1.45$

12. Printing a copy to underline information 2.10

15. Using references like online dictionary $\quad 3.45$

21. Paraphrasing to better understand 2.26

25. Going back and forth to find relationships $\quad 2.50$

29. Asking myself questions about text 2.10

37. Translating from English into my native language $\quad 3.80$

38. Thinking in both English and my mother tongue $\quad 3.50$ 


\section{CONCLUSION}

The results of this study showed that the participants employed low to moderate use of metacognitive strategies when reading online. This finding is similar to Zhang and Duke's (2008) conclusion that reading skills and strategies cannot be simply transferred from the print medium to the online environment. Research has also suggested that readers can transfer some but not all of their reading strategies from paper to the online environment. (Anderson, 2003; Atari \& Radwan, 2013; Henry, 2006; Incecay, 2013) and have revealed that not only students but also teachers might not be aware of the nature and role of metacognitive online reading strategies. In effect, Anderson (2003) recommends that "rather than focusing students' attention only on issues related to reading content, effective teachers should structure a learning atmosphere where thinking about what happens during online reading will lead to stronger learning skills" (p. 5). It can be concluded that there is a need to raise awareness among students and teachers about metacognitive strategy use when reading online because it can enhance reading comprehension and enable learners to reap the benefits of being connected to the limitless knowledge possibilities the internet can provide.

\section{REFERENCES}

[1] Anderson, N. (2003). Scrolling, clicking, and reading English: Online reading strategies in a second/foreign language. Reading Matrix: An International Online Journal, 3(3), 1-33.

[2] Atari, O. F. \& Radwan, A. A. (2013). Translator training: A mirror image of EFL pedagogy inadequacies. Arab World English Journal, 4, $5-25$.

[3] Flavell, J. H. (1976). Metacognitive aspects of problem-solving. In L. B. Resnick (Ed.), The nature of intelligence (pp. 231-236). Hillsdale, NJ: Erlbaum.

[4] Block, C.C., \& Pressley, M. (Eds.). (2002). Comprehension instruction: Research-based best practices. New York: Guilford.

[5] Henry, L.A. (2005). Information Search Strategies on the Internet: A Critical Component of New Literacies. Webology, 2(1), 1-11

[6] İncecay, G. (2013). Metacognitive online reading strategies applied by EFL students. Journal of Theory \& Practice in Education (JTPE), 9(4), 390-407

[7] Kim, N. (2011). Integrated metacognitive online reading strategy use by Korean EFL university students (Doctoral dissertation). Retrieved from ProQuest Dissertations \& Theses Global. (UMI No. 919077789)

[8] Konishi, M. (2003). Strategies for reading hypertext by Japanese ESL learners. The Reading Matrix, 3(3), 97-119.

[9] Kramarski, B., \& Feldman, Y. (2000). Internet in the classroom: Effects on reading comprehension, motivation and metacognitive awareness. Education Media International, 37(3), 149-155. https://doi.org/10.1080/09523980050184709

[10] Kymes, A. (2005). Teaching online comprehension strategies using think-alouds. Journal of Adolescent \& Adult Literacy, 48(6), 492-500. https://doi.org/10.1598/JAAL.48.6.4

[11] Liu, I., Wu, S., \& Ko, H. (2014). Learning reading strategies with online discussion. Journal of Educational Computing Research, 50(2), 231247. https://doi.org/10.2190/EC.50.2.e

[12] Mokhtari, K., \& Reichard, C. A. (2002). Assessing students' metacognitive awareness of reading strategies. Journal of Educational Psychology, 94(2), 249-259. https://doi.org/10.1037/0022-0663.94.2.249

[13] Mokhtari, K., \& Sheorey, R. (2002). Measuring ESL students' awareness of reading strategies. Journal of Developmental Education, 25(3), 2-10.

[14] Sutherland-Smith, W. (2002). Weaving the literacy Web: Changes in reading from page to screen. The Reading Teacher, 55, 662-669.
[15] O'Malley, J. \& Chamot, A. (1990). Learning strategies in second language acquisition. Cambridge, UK: Cambridge University Press. https://doi.org/10.1017/CBO9781139524490

[16] Ostovar-Namaghi, S., \& Noghabi, A. (2014). A comparison of perceived use of the metacognitive reading strategies by Iranian master of science students for hypertext and printed academic materials. Journal of Language Teaching \& Research, 5(4), 865-872. https://doi.org/10.4304/jltr.5.4.865-872

[17] Palnincsar, A.S., \& Brown, D.A. (1987). Enhancing instructional time through attention to metacognition. Journal of Learning Disabilities, 20(2), 66-75. https://doi.org/10.1177/002221948702000201

[18] Zhang, Sh.; Duke, N. K. 2008. Strategies for Internet Reading with Different Reading Purposes: A Descriptive Study of Twelve Good Internet Readers. Journal of Literacy Research. 40: 128-162. https://doi.org/10.1080/10862960802070491 